\title{
Hospital transfer for primary coronary angioplasty in high risk patients with acute myocardial infarction
}

\author{
E Straumann, S Yoon, B Naegeli, J Frielingsdorf, A Gerber, E Schuiki, O Bertel
}

\begin{abstract}
Objective-To investigate the feasibility, safety, and associated time delays of interhospital transfer in patients with acute myocardial infarction for primary percutaneous transluminal coronary angioplasty (PTCA).

Design and patients-Prospective observational study with group comparison in a single centre. 68 consecutive patients with acute myocardial infarction transferred for primary PTCA from other hospitals (group A) were compared with 78 patients admitted directly to the referral centre
\end{abstract} (group B).

Main outcome measures-Patient groups were analysed with regard to baseline characteristics, time intervals from onset of chest pain to balloon angioplasty, hospital stay, and follow up outcome.

Results-Patients in group A presented with a higher rate of cardiogenic shock initially than patients in group B $(25 \% v$ $6 \%, p=0.01$ ) and had been resuscitated more frequently before PTCA (22\% v 5\%, $p=0.01)$. No deaths or other serious complications occurred during interhospital transfer. Median transfer time was 63 (range 40-115) minutes for helicopter transport (median 42 (28-122) $\mathrm{km}$, $\mathrm{n}=14)$, and $50(18-110)$ minutes by ground ambulance (median $8(5-68) \mathrm{km}$, $n=54)$. The median time interval from the decision to perform coronary arteriography to balloon inflation was 96 (45243) minutes in group $A$ and 52 (17-214) minutes in group $B(p=0.0001)$. In transferred patients (group $A)$ the transportation associated delay and the longer in-hospital median decision time (50 (101120) minutes in group $A v 15(0-210)$ minutes in group $B, p=0.002$ ) concurred with a longer total period of ischaemia (239 (114-1307) minutes in group A $v 182$ (75-1025) minutes in group $B, p=0.02$ ) since the beginning of chest pain. Success of PTCA (TIMI 3 flow in $95 \%$ of all patients), in-hospital mortality $(7 \% v 9 \%$, mortality for patients not in cardiogenic shock $0 \% \quad v \quad 4 \%$ ), and follow up after median 235 days was similarly favourable in groups $A$ and $B$, respectively. Only one hospital survivor (group A) died during follow up.

Conclusion-Interhospital transport for primary PTCA in high risk patients with acute myocardial infarction is safe and feasible within a reasonable period of time. Short and medium term outcome is favourable. Optimising the decision process and transport logistics may further improve outcome by reducing the total time of ischaemia.

(Heart 1999;82:415-419)

Keywords: acute myocardial infarction; primary percutaneous transluminal coronary angioplasty; hospital transfer; time delay

Randomised trials have shown that primary percutaneous transluminal coronary angioplasty (PTCA) may offer advantages over thrombolysis in treating acute myocardial infarction. ${ }^{1-4}$ Infarct related vessel patency is achieved more frequently and persistently with PTCA compared to thrombolytic treatment, even if second and third generation thrombolytics are used. ${ }^{5-7}$ Documented benefits of primary PTCA are lower mortality, lower reinfarction rate, and fewer cerebrovascular accidents. ${ }^{124}$

However, most patients with acute myocardial infarction are admitted to hospitals without facilities for primary PTCA. Even in patients at high risk who may benefit most from primary PTCA, transport associated risks and delays may offset the advantages of primary PTCA. ${ }^{8}$

We therefore studied prospectively the feasibility and safety of patient transfer for primary PTCA in high risk patients with acute myocardial infarction admitted primarily to hospitals without PTCA facilities.

\section{Patients and methods}

The Triemli hospital is a tertiary referral centre with 24 hour service for acute coronary interventions. In a single catheterisation laboratory approximately 1500 diagnostic studies and 700 PTCA procedures are performed annually. All patients receiving invasive diagnostic studies or PTCA (primary and rescue) during the first 24 hours of an acute myocardial infarction were included prospectively into a registry. Approximately half of these patients were transferred from other hospitals.

Patients are considered to have an acute myocardial infarction when at least two of the three following criteria are fulfilled: persistent chest pain suggestive for myocardial infarction of at least 30 minutes duration; at least $1 \mathrm{~mm}$ of ST elevation in at least two consecutive leads or left bundle branch block; or a significant rise in 
Table 1 Criteria used for a primary PTCA policy in infarct patients initially admitted to the referring hospitals

\begin{tabular}{ll} 
Cardiogenic shock & $\begin{array}{l}\text { Systolic blood pressure }<90 \mathrm{~mm} \mathrm{Hg},>30 \text { minutes despite } \\
\text { volume replacement, and clinical signs of hypoperfusion and/or } \\
\text { urinary output }<20 \mathrm{ml} / \mathrm{h}\end{array}$ \\
$\begin{array}{l}\text { Extensive anterior infarction } \\
\text { Extensive inferior infarction }\end{array}$ & $\begin{array}{l}\text { Inferion infarction with ST segment depression in precordial } \\
\text { leads }\end{array}$ \\
$\begin{array}{l}\text { Inferior infarction with right } \\
\text { ventricular involvement }\end{array}$ & $\begin{array}{l}\text { Inferior infarction with ST elevation in right precordial leads } \\
\text { Recurrent infarction } \\
\begin{array}{l}\text { Contraindication for } \\
\text { thrombolysis }\end{array}\end{array}$ \\
$\begin{array}{l}\text { Age over 70 years } \\
\text { Diabetes mellitus }\end{array}$ & $\begin{array}{l}\text { Recent major surgery, prolonged mechanical resuscitation, } \\
\text { gastrointestinal bleeding }\end{array}$ \\
\hline
\end{tabular}

Table 2 Baseline characteristics

\begin{tabular}{llll}
\hline & $\begin{array}{c}\text { Group } A \\
(n=68)\end{array}$ & $\begin{array}{c}\text { Group } B \\
(n=78)\end{array}$ & p value \\
\hline Age (years) (mean (SD)) & $56(12)$ & $59(13)$ & NS \\
Age over 70 years & 11 & 22 & 0.08 \\
Female & 9 & 15 & $\mathrm{NS}$ \\
Multivessel disease & 43 & 37 & $\mathrm{NS}$ \\
Anterior infarction & 35 & 34 & $\mathrm{NS}$ \\
Cardiogenic shock before PTCA & 17 & 5 & 0.01 \\
Resuscitation before PTCA & 15 & 1 & 0.01 \\
Intubated on ventilation & 8 & 21 & 0.02 \\
Contraindication for thrombolysis & 39 & 21 & 0.01 \\
Diabetes mellitus & 25 & & $\mathrm{NS}$ \\
\hline
\end{tabular}

Value are number of patients except where stated.

creatine kinase $\mathrm{MB}$ isoenzyme (CK-MB) to at least twice the upper limit of normal values.

Cardiogenic shock was predefined as: noninvasively or invasively measured blood pressure persistently (>30 minutes) below $90 \mathrm{~mm} \mathrm{Hg}$ despite adequate volume replacement; and clinical signs of hypoperfusion, urinary output below $20 \mathrm{ml} /$ hour, or both.

Two patient groups were prospectively studied. Group A included all patients who were admitted for acute myocardial infarction into other hospitals without PTCA facilities and in whom primary PTCA had been chosen as the initial treatment because of the presence of one or more of the risk factors summarised in table 1. Group B consisted of infarct patients primarily admitted to our hospital in whom primary PTCA was the preferred treatment strategy.

Patients transferred for rescue PTCA, who were primarily treated medically with thrombolytics, were excluded from the analysis.

Time intervals for all patients were recorded prospectively (pain onset, hospital admission time, decision to angiography, transport, arrival time at the referral centre, arterial puncture, and first balloon inflation). Angiographic assessment included extent of disease (one to three vessel disease) and TIMI flow grade of the infarct related artery pre- and post-PTCA. CK-MB and time to peak CK-MB were measured routinely (after $2,4,8,12$, and 24 hours), and troponin I measurements were done routinely in the last 58 patients.

Table 3 Patient transfer

\begin{tabular}{lclcl}
\hline & $\begin{array}{l}\text { Ground } \\
\text { ambulance } \\
(n=54)\end{array}$ & $\begin{array}{l}\text { Helicopter } \\
(n=14)\end{array}$ & Total $(n=68)$ & $p$ Value \\
\hline Distance $(\mathrm{km})$ & $8(5-68)$ & $42(24-122)$ & $9(5-122)$ & 0.0001 \\
Transfer time (min)* & $50(18-110)$ & $63(40-115)$ & $55(18-115)$ & 0.02 \\
\hline
\end{tabular}

Values are median (range).

*Total transfer time from decision to arrival in catheter laboratory.
Follow up included a clinical interview, physical examination, and a bicycle exercise test. Follow up was scheduled four months after PTCA, and was updated systematically to March 1998. If signs or symptoms of ischaemia occurred, coronary angiography was repeated.

STATISTICAL ANALYSIS

Student's $t$ test for continuous and $\chi^{2}$ analysis for categorical variables was used to evaluate differences between groups. Time intervals and transfer distances were not distributed normally, and were therefore expressed in median and range, and Mann-Whitney $U$ test was performed to calculate differences between groups. A two tailed $\mathrm{p}$ value $<0.05$ was considered significant.

\section{Results}

BASELINE CHARACTERISTICS

A total of 146 consecutive patients with acute myocardial infarction and primary PTCA within 24 hours after onset of symptoms were included in this analysis. A further 70 patients with rescue PTCA were excluded. Patient characteristics are given in table 2 for patients transferred for primary PTCA (group A) compared to patients directly admitted to our hospital (group B). Significantly more patients in group A were in cardiogenic shock, were resuscitated, or had a contraindication for thrombolysis than patients in group B. Eight patients were mechanically ventilated during interhospital transfer. Three patients who died before transportation in cardiogenic shock were not included in the analysis.

\section{TRANSFER}

Transfer distance between hospitals ranged from $5-122 \mathrm{~km}$ (table 3 ). Patients were transferred by helicopter $(n=14)$, or by ground ambulance $(n=54)$. Median distance was 42 (range 24-122) km for helicopter transport, and $8(5-68) \mathrm{km}$ for ambulance transport. Absolute transport time was shorter by helicopter transfer than by ground ambulance (37 (7-60) minutes $v 47$ (15-126) minutes), but total transfer time as calculated from time of decision for PTCA to arrival in the catheterisation laboratory was slightly longer for helicopter transfer $(\mathrm{p}=0.02)$. No patient died during transport. Patients in cardiogenic shock did not deteriorate during transport.

\section{DELAYS}

Prehospital delay was not significantly different between groups, but in-hospital decision time and decision to angiography delay was significantly longer in group A than group B. First balloon inflation was performed median 20 minutes after puncture of the femoral artery in both groups. Overall median delay from symptom onset to balloon inflation was 239 (114-1307) minutes in group A and 182 (751025) minutes in group $B(p=0.02)$ (table 4$)$.

ANGIOGRAPHIC RESULTS AND IN-HOSPITAL COURSE

Overall angiographic success rate was $96 \%$ (TIMI flow 2 and 3), and TIMI 3 flow was 
Table 4 Median (range) time intervals (minutes)

\begin{tabular}{lccl}
\hline & Group $A(n=68)$ & Group B $(n=78)$ & $p$ Value \\
\hline Prehospital delay & $105(15-1120)$ & $130(0-705)$ & 0.1 \\
In-hospital decisions delay & $50(10-465)$ & $15(0-210)$ & 0.0001 \\
Door to angiography (catheter in artery) & $20(10-100)$ & $43(14-268)$ & 0.0001 \\
Decision to angiography & $76(37-160)$ & $32(8-148)$ & 0.0001 \\
Needle to balloon inflation delay & $20(08-83)$ & $20(9-66)$ & NS \\
Decision to balloon inflation delay & $96(45-243)$ & $52(17-214)$ & 0.0001 \\
Onset of symptoms to balloon inflation delay & $239(114-1307)$ & $182(75-1025)$ & 0.02 \\
\hline
\end{tabular}

Table 5 In-hospital course

\begin{tabular}{|c|c|c|c|}
\hline & Group $A(n=68)$ & Group B $(n=78)$ & $p$ Value \\
\hline Angiographic success rate (\%) & 96 & 96 & NS \\
\hline TIMI 3 flow (\%) & 94 & 95 & NS \\
\hline In-laboratory deaths $(n)^{\star}$ & 2 & 1 & NS \\
\hline In-hospital deaths $(\mathrm{n})^{\star}$ & 3 & 6 & NS \\
\hline In-hospital reinfarction ( $\mathrm{n}$ ) & 2 & 0 & NS \\
\hline Mean (SD) CK-MB (u/l) & 313 (226) & $272 \quad(222)$ & NS \\
\hline Mean (SD) time CK-MB peak (h) $\dagger$ & $11.9(5.1)$ & $10.6(5.2)$ & NS \\
\hline Median (range) hospital stay (days) & $9 \quad(1-32)$ & $6 \quad(1-71)$ & 0.02 \\
\hline
\end{tabular}

*All transferred patients who died were in cardiogenic shock before PTCA; †After symptom onset.

Table 6 Follow up

\begin{tabular}{|c|c|c|c|}
\hline & Group $A(n=68)$ & Group $B(n=78)$ & p Value \\
\hline $\begin{array}{l}\text { Median follow up (days) } \\
\text { (range) }\end{array}$ & $\begin{array}{l}220 \\
(14-788)\end{array}$ & $\begin{array}{l}296 \\
(14-934)\end{array}$ & 0.04 \\
\hline \multicolumn{4}{|l|}{ Events } \\
\hline Follow up deaths (n) & 1 & 0 & NS \\
\hline Reinfarctions (n) & 2 & 3 & NS \\
\hline Repeat angiography (n) & 17 & 13 & NS \\
\hline Target vessel reinterventions (n) & 8 & 5 & NS \\
\hline PTCA (n) & 7 & 2 & 0.03 \\
\hline CABG (n) & 1 & 3 & NS \\
\hline \multicolumn{4}{|l|}{ Symptoms at final visit } \\
\hline \multicolumn{4}{|l|}{ Angina pectoris (\%) } \\
\hline None & 88 & 91 & NS \\
\hline NYHA II & 10 & 9 & NS \\
\hline NYHA III & 2 & 0 & NS \\
\hline \multicolumn{4}{|l|}{ Dypnoea (\%) } \\
\hline NYHA I & 76 & 69 & NS \\
\hline NYHA II & 24 & 31 & NS \\
\hline NYHA III & 0 & 0 & NS \\
\hline
\end{tabular}

NYHA, New York Heart Assocation.

achieved in $95 \%$ (table 5). Stents were used in $67 \%$ of patients, abciximab in $27 \%$, and an intraortic balloon pump was inserted in $10 \%$. Two transferred patients died during PTCA and three transferred patients died during hospital stay because of cardiogenic shock and multiorgan failure, despite angiographically successful angioplasty. All transferred patients who died were in cardiogenic shock before PTCA. Hospital mortality was similar in both groups; for all non-shock patients it was $2 \%$ ( $0 \%$ and $4 \%$ in groups $\mathrm{A}$ and $\mathrm{B}$, respectively). No emergency coronary artery bypass grafting had to be performed.

Peak CK-MB concentration and time to peak CK-MB were similar in both groups.

Reinfarction during hospital stay occurred in two transferred patients (non-Q wave infarctions); both had immediate successful repeat angioplasty.

Total hospital stay was longer for transferred patients; most were transferred back to the referring hospital the day after the intervention with the exception of patients in cardiogenic shock.

FOLLOW UP

A complete follow up was obtained in all but two patients (tourists from abroad) (table 6). During long term follow up (median 235 days) only a 50 year old man with anterior infarction died; he initially had been resuscitated in hospital because of ventricular fibrillation and was transferred for angiography in persistent cardiogenic shock. PTCA of the left anterior descending artery was successful, the patient recovered promptly, and he did well after discharge until he died suddenly two weeks later. Non-Q wave infarction during follow up occurred in two patients in group A and three patients in group B.

Frequency of target vessel reintervention because of recurrence of symptoms (PTCA and coronary artery bypass grafting) was similar in both groups, although target vessel re-PTCA was performed more often in group A than in group $B$.

Prevalence of angina pectoris and dyspnoea were evenly distributed in both groups.

\section{Discussion}

Possible shortcomings of using PTCA as a primary treatment in patients with acute myocardial infarction include the delay to reperfusion of the infarct related artery and the risk involved transferring a patient to a hospital with a fully equipped and staffed catheterisation laboratory. ${ }^{89}$

In the present study the additional delay from the beginning of symptoms to balloon inflation was 57 minutes for transferred compared to primarily admitted patients. This delay was not only caused by the time required for transportation, but also because of an additional in-hospital decision time of 35 minutes.

Thus, there is potential to improve further patient management assigned to primary PTCA. The period of ischaemia can be shortened by a faster in-hospital decision to perform coronary angiography, and by optimising transport organisation. The present data show that delays from decision to balloon inflation may be well in the range of 60-90 minutes even when distances are more than $100 \mathrm{~km}$, given a fast track organisation between hospitals, including patient transport organisations. These delays compare favourably to those reported in the global use of strategies to open occluded coronaries arteries (GUSTO IIb) angiographic substudy (time from presentation to angioplasty 114 minutes), in which patients did not have to be transferred between hospitals for PTCA. ${ }^{3}$ Shorter delays by improved organisation of catheterisation laboratory facilities may even augment the potential benefit of primary PTCA in acute myocardial infarction, since time to reperfusion is strongly associated with subsequent mortality, as shown for thrombolysis, which may apply for primary PTCA as well..$^{10-13}$

The transferred patients were at high risk for infarct related complications. Despite severely impaired haemodynamic conditions in a substantial proportion of transferred patients, no death occurred during transfer. Interhospital transfer was feasible and safe even for unstable patients with controlled mechanical ventilation. Hospital mortality and follow up was similar in both transferred and primarily admitted patients. 
There are few data on the effects of interhospital transfer of patients with acute myocardial infarction. The results of two very recent reports are equivocal. While in a study by Zijlstra et al the risk of death because of transportation was low, and the effect on total ischaemia time was small, ${ }^{14}$ a recent abstract from Tiefenbrun et al reported a significantly higher hospital mortality of $7.7 \%$ in patients with acute myocardial infarction being transported for PTCA compared to $5 \%$ being primarily admitted. ${ }^{9}$ On the other hand some preliminary data from the "PRAGUE" pilot trial have been demonstrated recently, indicating the feasibility and safety of transport of patients with acute myocardial infarction. ${ }^{15}$

Obviously, differences in outcome can be explained by patient selection and different risk profiles present before transfer and PTCA. The overall favourable outcome in our patients, characterised by a high prevalence of factors indicating a substantially increased mortality risk at the time of presentation, may point to the need for a prospective randomised study comparing an early aggressive revascularisation strategy (including patient transfer for PTCA in specialised centres) with a primarily conservative management in patients admitted to hospitals without PTCA facilities.

Additional treatment options, such as the use of stents, abciximab, and intra-aortic balloon counterpulsation in shock patients, may have favourably influenced the short and medium term outcome in the present study. Further randomised trials evaluating the optimal treatment for the majority of infarct patients should therefore not only focus on the comparison of PTCA versus conservative management. ${ }^{16-20}$ Instead, a more comprehensive revascularisation approach, available in specialised centres only (stenting, abciximab, intra-aortic balloon counterpulsation), should be compared to the best conservative treatment on site in hospitals without invasive treatment facilities.

Our data and the results reported by others indicate that primary PTCA may be a reasonable treatment option for a substantial number of infarct patients who are hospitalised primarily in hospitals without primary access to a fully equipped catheterisation laboratory. ${ }^{14}{ }^{15}$ If confirmed in randomised studies this finding may substantially influence the management of acute myocardial infarction, especially in high risk patients, since present invasive revascularisation procedures are restricted to a few patients in the first hours of acute myocardial infarction.

A further optimisation of hospital decision and between hospital transfer could be obtained if a fast track for acute coronary syndromes is clearly defined in each institution-including written guidelineswith very early contact to the referral centre. This could allow earlier organisation of the transfer as well as enable preparation of the interventional unit in the referral centre. Principles of such a strategy have been outlined recently. ${ }^{21}$
STUDY LIMITATIONS

Although data were drawn from a prospectively conducted registry, this is not a controlled randomised study comparing transferred acute myocardial infarction patients for primary PTCA with acute myocardial infarction patients who were treated conservatively and not transferred. However, patients were selected by the referring physician and the interventional cardiologist because they represented a high risk population. Whether the apparent benefit would translate into a lower risk group remains to be determined.

\section{CONCLUSION}

The present data indicate that even in high risk groups of patients with acute myocardial infarction, interhospital transfer for primary PTCA can be performed with favourable short and medium term outcomes. The associated risks and time delays are reasonable. Only a large randomised trial can establish the optimal treatment for patients with acute myocardial infarction primarily hospitalised in institutions without invasive treatment facilities.

1 Weaver WD, Simes J, Betriu A, et al. Comparison of primary coronary angioplasty and thrombolytic therapy for acute myocardial infarction. $7 A M A$ 1997;278:2093-8.

2 Grines CL, Browne KF, Marco J, et al, for the Primary Angioplasty in Myocardial Infarction Study Group. A comparison of immediate angioplasty with thrombolytic therapy for acute myocardial infarction. $N$ Engl $\mathcal{F}$ Med 1993;329:673-82.

3 GUSTO IIb Angioplasty Substudy Investigators. A clinical trial comparing primary coronary angioplasty with tissue plasminogen activator for acute myocardial infarction. $N$ Engl f Med 1997;336:1621-8.

4 Zijlstra F, de Boer MJ, Hoorntje JCA, et al. A comparison of immediate coronary angioplasty with intravenous streptokinase in acute myocardial infarction. $N$ Engl $f \mathrm{Med}$ 1993;328:680-4.

5 GUSTO I Angiographic Investigators. The effects of tissue plasminogen activator, streptokinase, or both on coronary artery patency, ventricular function, and survival after artery patency, ventricular function, and survival after 22 .

6 Cannon CP, McCabe CH, Gibson CM, et al. TNK-tissue plasminogen activator in acute myocardial infarction. Results of the thrombolysis in myocardial infarction (TIMI) 10: a dose-ranging trial. Circulation 1997;95:3516.

7 Bode C, Smalling RW, Berg G, et al. Randomised comparison of coronary thrombolysis achieved with double blind bolus reteplase (recombinant plasminogen activator) and front loaded, accelerated alteplase (recombinant tissue plasminogen activator) in patients with acute myocardial infarction: the RAPID II investigators. Circulation 1996;94: $891-8$.

8 Bellinger RL, Califf RM, Mark DB, et al. Helicopter transport of patients during acute myocardial infarction. $A m \mathcal{F}$

9 Tiefenbrun AJ, Chandra NC, Every NR, et al. High mortality in patients with myocardial infarction transferred for primary angioplasty: a report from the national registry or primary angioplasty: a report from the national registry of (suppl):A351.

10 GUSTO investigators. An international randomized trial comparing four thrombolytic strategies for acute myocardial infarction. N Engl f Med 1993;329:673-82.

1 Gruppo italiano per lo studio della streptochinasi nell'infarto miocardio (GISSI). Effectiveness of intravenous thrombolytic therapy in acute myocardial infarction. Lancet 1986;i:397-401.

12 ISIS-2 Collaborative Group. Randomised trial of intravenous streptokinase, oral aspirin, both, or neither among 17187 cases of suspected acute myocardial infarction: second international study group of infarct survival (ISIS-2). Lancet 1988;ii:349-360.

13 Simes RJ, Topol EJ, Homes DR Jr, et al. Link between the angiographic substudy and mortality in a large randomized trial of myocardial reperfusion: importance of early and complete infarct artery reperfusion. GUSTO-I investigacomplete infarct artery reperfusion 
14 Zijlstra F, van't Hof AWJ, Liem AL, et al. Transferring patients for primary angioplasty: a retrospective analysis of 104 selected high risk patients with acute myocardia infarction. Heart 1997;78:333-6.

15 Widimsky P, Groh L, Aschermann M, et al. Transport for primary PTCA: results of the pilot phase of the "PRAGUE" study - a national multicenter randomized study on patients with acute myocardial infarction presenting to community hospitals. Circulation 1998;98(suppl):I-771.

16 Neumann FJ, Walter H, Richardt G, et al. Coronary Neumann FJ, Walter H, Richardt G, et al. Coronary
Palmaz-Schatz stent implantation in acute myocardial Palmaz-Schatz stent implantation

17 Antoniucci D, Valenti R, Santorno GM, et al. Systematic direct angioplasty and stent-supported direct angioplasty therapy for cardiogenic shock complicating acute myocardial infarction: in-hospital and long-term survival. $\mathcal{f} \mathrm{Am}$ Coll Cardiol 1998;31:294-300.
18 Lefkovits J, Ivanhoe RI, Califf RM, et al for the EPIC investigators. Effects of platelet glycoprotein IIb/IIIa receptor blockade by a chimeric monoclonal antibody (abciximab) on acute and six-month outcomes after percutaneous
transluminal coronary angioplasty for acute myocardial transluminal coronary angioplasty for acu
infarction. Am $\mathcal{f}$ Cardiol 1996;77:1045-51.

19 Kovack PJ, Rasak MA, Bates ER, et al. Thrombolysis plus aortic counterpulsation: improved survival in patients who present to community hospitals with cardiogenic shock. $\mathcal{F}$ Am Coll Cardiol 1997;29:1454-8.

20 Ohman EM, George BS, White CJ, et al for the randomized IABP study group. Use of aortic counterpulsation to improve sustained coronary artery patency during acute myocardial infarction: results of a randomized trial. Circulation 1994;90:792-9.

21 Serruys PW, Kay IP. Cardiogenic shock: a failure in reperfusion. Time for a strategic chance? Eur Heart f 1999; 20:88-9. 